\title{
LA NATURPHILOSOPHIE EN ESPAÑA. LA RECEPCIÓN DEL EVOLUCIONISMO EN EL ENTORNO DE LA TRADICIÓN KRAUSISTA
}

\author{
Julio Simó Ruescas
}

I.E.S. Jaime Vera, Madrid

\section{RESUMEN}

Se analiza aquí la recepción del evolucionismo por parte de los naturalistas españoles vinculados al krausismo, un evolucionismo que está más cerca de la naturphilosophie alemana que del darwinismo. Este análisis se hace sobre las aportaciones realizadas en la década de 1870 por Augusto González de Linares y Alfredo Calderón y una aportación posterior, más cercana al darwinismo, de Ignacio Bolívar y Salvador Calderón.

PALABRAS CLAVE: Darwinismo, naturphilosophie, krausismo, España, siglo XIX

\section{SUMMARY}

We are analysing here the reception of evolutionism made by spanish naturalist attached to krausism, an evolutionism more related to german naturphilosphie than to darwinism. This analysis is based in the contributions made by Augusto González de Linares and Alfredo Calderón in the 1870s, as well as a later contribution closer to darwinism, by Ignacio Bolívar and Salvador Calderón.

KEY WORDS: Darwinism, naturphilosophie, krausism, Spain, $19^{\text {th }}$ century.

El 30 de abril de 1882, el Boletín de la Institución Libre de Enseñanza dedicaba toda su primera página a un artículo necrológico sobre Darwin, fallecido diez días antes y que había sido nombrado profesor honorario de la Institución en 1878. En el número siguiente, del 16 de mayo, aparece un artículo de Gumersindo de Azcárate titulado Darwin juzgado por un canónigo, en el que se daba cuenta de la oración fúnebre pronunciada por el obispo Liddon en la catedral de Londres. Sin apenas comentario por su parte, Azcárate quería mostrar el contraste entre la actitud tolerante y el tipo de relación que existía entre la ciencia y la religión en Gran Bretaña, tal y como demostraban las 
palabras de Liddon, y la fuerte oposición que la Iglesia española había mantenido hacia la teoría de la evolución.

Pero la acogida entusiasta que los fundadores de la Institución Libre de Enseñanza dispensaron a Darwin y a su obra, no procede sólo, ni siquiera principalmente, de la capacidad explicativa de la teoría de la evolución por medio de la selección natural para dar cuenta de los procesos naturales. Antes bien, en el terreno experimental, para estos filósofos y naturalistas de la tradición krausista, resulta difícil, e incluso imposible, demostrar la veracidad de la teoría de Darwin. Si la han asumido, si han batallado públicamente por ella, es sobre todo por dos razones. Una, por el carácter enteramente progresista que la teoría tiene a los ojos de estos liberales que ponen sus mayores empeños en superar los obstáculos impuestos por la tradición al desarrollo de las fuerzas productivas y en liberar a la ciencia del peso de la tutela impuesta por la escolástica. Otra, porque, en palabras de Augusto González de Linares, «la nueva idea era en sí misma mucho más unitaria, más racional, más adecuada a las exigencias de nuestra razón, más conforme, por lo tanto, a la Naturaleza misma, que el antiguo dogma, incapaz de satisfacer, con su variedad primitiva e irreductible de formas orgánicas, la aspiración a la unidad ingénita en el espíritu humano, obligado a reflejar en sí mismo el organismo universal que forma la complexión entera de las cosas» ${ }^{1}$.

Vemos de esta forma que, independientemente de que algunos de los naturalistas de esta escuela llevaran a cabo un trabajo de investigación científica positiva ${ }^{2}$ de acuerdo a los principios básicos de la teoría de la evolución, la recepción del evolucionismo tuvo un carácter apriorístico, encaminado a construir una nueva metafísica, como algunos de los miembros de la escuela declararon explícitamente, al menos en sus primeros escritos ${ }^{3}$.

1 GonZÁlEZ DE LiNARES, A. (1879), «La geometría y la morfología de la naturaleza», Revista de España, t.66, $n^{\circ} 264$, pág. 480.

2 Acerca de las relaciones entre krausismo y positivismo cfr. Núñez Ruiz, D. (1975), La mentalidad positiva en España: desarrollo y crisis. Túcar, Madrid. También sobre las diferentes corrientes entre el krausismo y el positivismo, cfr. SALA CATALÁ, J. (1987), Ideología y ciencia biológica en España entre 1860 y 1881. La difusión de un paradigma. CSIC, Madrid.

3 A este respecto, Santos Casado ha señalado cómo, si bien los krausistas fueron incorporando los principales presupuestos del positivismo científico, «nunca perdieron, sin embargo, un particular modo de aproximarse a las grandes cuestiones científicas, lo que les llevó, entre otras cosas, a desarrollar una serie de versiones particulares de un, valga la expresión, evolucionismo trascendente». CASADO DE OTAOLA, S. (2001), La escritura de la naturaleza. Antología de naturalistas españoles 1868-1936. Caja Madrid, Madrid, pág. 32. 
De acuerdo con esto, nos proponemos caracterizar aquí la Filosofía de la Naturaleza del krausismo español y estudiar la forma en que una serie de científicos y pensadores vinculados a la tradición krausista recogen la teoría de la evolución y la peculiaridad que presenta su interpretación. Para ello, nos vamos a fijar principalmente en quienes consideramos como los principales codificadores de la Filosofía de la Naturaleza de tradición krausista en los años setenta del siglo XIX, Augusto González de Linares y Alfredo Calderón y Arana, para dedicar nuestra atención más tarde a la forma en que, ya a principios del siglo XX, la teoría aparece en la obra de dos científicos vinculados en un principio a esta tradición, pero que representaron una «desviación experimentalista» dentro de ella, Ignacio Bolívar y Salvador Calderón.

\section{EVOLUCIONISMO Y FILOSOFÍA DE LA NATURALEZA EN EL KRAUSISMO ESPAÑOL}

Es, sin duda, sobradamente conocido por cualquiera que esté familiarizado con las circunstancias de la introducción del krausismo en España, que una cosa es la filosofía de Krause y otra la versión que de esa filosofía se introdujo en España de la mano de Julián Sanz del Río, distinción que ha sido señalada repetidas veces por distintos autores. Baste citar a este respecto entre las más recientes la opinión, aunque matizada, de Luis Montiel, quien, tras reconocer esa diferencia entre filosofía de Krause y krausismo español, considera, con todo, que no es exacta la opinión de algunos krausistas, como Giner, de que El ideal de la humanidad para la vida de Julián Sanz del Río era una obra original y no una mera traducción de Krause. Para Montiel, el libro de Sanz del Río es «el resultado de un esfuerzo de quien, valorando altamente el texto que vierte al castellano, en parte renuncia a la esforzada labor de la traducción y en parte pretende exponer, con fidelidad pero también tomándose amplias libertades, la doctrina en él contenida» ${ }^{4}$.

Por su parte Elías Díaz expresó esa diferencia entre filosofía de Krause y krausismo español, o mejor, entre momentos distintos de la introducción del krausismo en España, identificando dos etapas en el desarrollo y difusión de la filosofía krausista en España. Una primera, centrada en Krause y Sanz del Río, desde 1854 hasta 1869 ó 1875, y una segunda, centrada en Giner y la

4 Montiel, L. (1995), «Las consecuencias de una elección para la filosofía de la medicina española: Krause frente a Schelling», en ARQUIOLA, E. y MARTínez PÉrEZ, J. (coords.), Ciencia en expansión. Estudios sobre la difusión de las ideas científicas y médicas en España (siglos XVIII-XX). Editorial Complutense, Madrid, pág. 147. 
Institución Libre de Enseñanza que abarca desde 1875 hasta 1915 (muerte de Giner) ó 1917 (muerte de Azcárate), etapa esta también llamada por diversos autores «krausismo abierto», en la que la tradición krausista española se ve influida por tendencias hegelianas, positivistas o neokantianas (también schelingianas en nuestra opinión) y en la que, en palabras de Joaquín Xirau citadas por Elías Díaz, «el krausismo español no es un sistema filosófico completo y acabado (...). Es más bien una disciplina moral (...) (que) detesta tan sólo la opaca y anquilosada osamenta de la escolástica decadente», palabras que llevan a Elías Díaz a concluir que «lo fundamental del krausismo (...) será la libertad de investigación, la afirmación de la libertad de conciencia» ${ }^{5}$.

Sin compartir plenamente estas afirmaciones pues pensamos que sí existe cierta voluntad de sistema incluso en esta segunda etapa del krausismo español, creemos que sirven para describir la pluralidad de influencias y una cierta ambigüedad de la filosofía krausista tal y como aparece expuesta a partir de la década de 1870. Para el asunto que aquí nos ocupa, es decir la formulación de una Filosofía de la Naturaleza de la tradición krausista española, esto nos plantea el problema de saber qué krausismo es del que estamos tratando y cuál es la influencia principal que experimenta esa filosofía natural. Según expondremos a continuación, en nuestra opinión, la tarea de los principales codificadores de esta Filosofía de la Naturaleza krausista de la década de 1870 se acerca a la corriente del idealismo alemán que arranca con Schelling ${ }^{6}$, por lo que nos atrevemos a caracterizar a esa Filosofía de la Naturaleza de la tradición krausista española ${ }^{7}$ como una versión, peculiar eso sí, de la Naturp-

5 DíAZ, E. (1989), La filosofia social del krausismo español. Debate, Madrid, pág. 48. (primera edición de 1972)

6 Esta influencia de Schelling coincide además con una extensión del romanticismo filosófico en nuestro entorno cultural más cercano. Como indicó en su día Manuel Sacristán, «en Francia no parece que la noción (de romanticismo filosófico) se haya abierto paso hasta finales de ese siglo (el XIX), casi cincuenta años después de la muerte de Schelling (1854) y veintiuno después de morir el más frenético, y acaso el más mediocre, de todos los filósofos románticos, Immanuel Hermann Fichte, hijo de Fichte el de verdad (1879)». SACRISTÁN, M. (1984), «Al pie del Sinaí romántico. Sugestiones para leer Filosofía Romántica», en SACRISTÁn, M., Papeles de Filosofía. Panfletos y Materiales II. Icaria, Barcelona, págs. 338-339. (primera edición en la revista Destino, 1967)

7 Por todo lo dicho anteriormente sobre filosofía de Krause y krausismo español, preferimos prudentemente hablar en general de tradición krausista española para referirnos a la corriente que representan una serie de personajes vinculados a la Institución Libre de Enseñanza y cuyos trabajos tienen un componente idealista que remite al idealismo alemán. Con todas las prevenciones expuestas, preferimos este término al de institucionismo, que engloba tal vez corrientes y propuestas más diversas. 
hilosophie, siguiendo en esto la distinción que hace Félix Duque entre Naturphilosophie y Philosophie der Natur, cuando indica que «Aunque la sutil distinción entre Naturphilosophie y Philosophie der Natur escapa a toda traducción en castellano, adviértase que el primer término -propio de Schelling y Baader y de la cohorte de sus seguidores - mienta algo así como una «inmersión» simpatética en el desarrollo de una Naturaleza entendida como un Organismo autoproductor, en el que el hombre descubre una analogía con el desarrollo de sus gradaciones psíquicas, gnoseológicas y prácticas. Philosophie der Natur, en cambio, apunta más bien a una «aplicación» de esquemas lógicos sobre los distintos niveles científicos, a fin de entresacar retroductivamente de éstos sus presupuestos metafísicos. La diferencia terminológica delata pues una diferencia radical de enfoque, tal como encontramos, por un lado, en Schelling, y por otro en Kant y Hegel» ${ }^{8}$.

Esa relación de la Filosofía de la Naturaleza del krausismo español con la corriente de la Naturphilosophie que arranca con Schelling viene determinada a nuestro entender por varios aspectos. En primer lugar, la recusación del atomismo y el empirismo, que tiene una vinculación estrecha con la crítica de Schelling a algunos autores representativos de estas corrientes. Así, acerca del empirismo del XVII, Schelling dirá que «Con la Naturphilosophie comienza, después de esa especie de investigación ciega y carente de ideas sobre la naturaleza que, desde la ruina causada a la filosofía por Bacon y a la física por Boyle y Newton se ha venido realizando por todas partes, un más elevado conocimiento de la Naturaleza» ${ }^{9}$. Una recusación que los naturalistas vinculados a la ILE extienden también al materialismo. En segundo lugar, la identidad de espíritu y naturaleza, característica de la filosofía schelingiana de la Naturaleza y fundamento de su Identitätslehre. En tercer lugar, la idea de la profunda unidad de la naturaleza, que un autor como Augusto González de Linares extiende también al mundo inorgánico estableciendo con ello las bases de un programa epistemológico que será asumido plenamente por científicos como Salvador Calderón o Francisco Quiroga. En cuarto lugar, la referencia explícita de la herencia que del idealismo alemán habían recibido personas como Augusto González de Linares y Alfredo Calderón y Arana, una referencia que se concreta sobre todo en Schelling, Oken y Carus. Así, mientras que Alfredo Calderón señala, como veremos más adelante, el prece-

8 DuQue, F. (1998), Historia de la Filosofia Moderna. La era de la crítica. Akal, Madrid, pág. 270.

9 Citado en Arquiola, E. y Montiel, L. (1993), La corona de las ciencias naturales. La medicina en el tránsito del siglo XVIII al XIX. CSIC, Madrid, pág. 92. 
dente de la «novísima filosofía natural española» en «la tradición científica de una escuela representada por tan ilustres pensadores como Schelling, Oken y Carus» ${ }^{10}$, Augusto González de Linares lamenta el maltrato que injustamente ha recibido la «tendencia idealista» de la Historia Natural por parte de «naturalistas empíricos, y en especial por su ilustre jefe, Jorge Cuvier» y cita entre los representantes de ese idealismo a Oken, Burdach y Carus, «cuyos nombres, dice, como de naturalistas que han profundizado verdaderamente en el estudio de los hechos son bien conocidos» ${ }^{11}$.

Pero si estos elementos dan cuenta de la filiación existente entre la $\mathrm{Na}$ turphilosophie y la Filosofía de la Naturaleza que exponen los naturalistas de la tradición krausista española, creemos que existe otro más de fondo que, además de mostrar esa relación, sirve de punto de partida para el desarrollo de una forma de evolucionismo que, aunque diferente al desarrollado por autores como, por ejemplo, Oken, hunde sus raíces en la Naturphilosophie iniciada por Schelling. Nos referimos a la idea de la naturaleza como «historia», una idea que, según intentaremos demostrar a lo largo de este trabajo se halla presente en los naturalistas vinculados a la Institución Libre de Enseñanza y que ha sido resaltada por distintos estudiosos de la filosofía del romanticismo alemán y, más concretamente, de la obra de Schelling como una de sus características ${ }^{12}$. Así, Arturo Leyte al referirse a la influencia de Herder sobre Schelling indica que «Schelling parece continuar la concepción de Herder según la cual la naturaleza es un organismo articulado producido permanentemente como resultado de fuerzas vivas y opuestas, que en realidad no es algo opuesto a la historia (...). Con Herder, y tras él Schelling, por «razón» habrá que entender en mayor medida no un ser, sino un devenir o proceso que se puede llamar naturaleza o historia, pero que en definitiva no es una instancia que funcione al modo de máquina, sino una vida» ${ }^{13}$. También Félix Duque, citando a Schelling, destaca la importancia que en la filosofía de éste

10 CALderón y ARANA, A. (1879), «Movimiento novísimo de la filosofía natural en España», Revista Europea, $n^{\circ} 269$, pág. 483.

11 GonZÁlez de LinARES, A. (1905), «Ensayo de una introducción al estudio de la Historia Natural», Boletín de la Institución Libre de Enseñanza (BILE), 1905, pág. 253.

12 Posteriormente a la formulación de la filosofía de la naturaleza del krausismo español, parece que esta relación entre naturaleza e historia, aunque con un contenido algo distinto, está también presente en el joven Ortega, si bien luego la rechazaría de forma determinante en su madurez. Cfr. Burón GonZÁlez, M. (1992), La Historia y la Naturaleza. Ensayo sobre Ortega. Akal, Madrid, págs. 19-33.

13 LEYTE, A. (1996), «Introducción. Una filosofía idealista de la naturaleza», en SCHELLING, F.W.J., Escritos sobre filosofía de la naturaleza. Alianza, Madrid, pág. 29. 
tiene la idea de naturaleza como «un producto que está siempre en devenir» ${ }^{14}$, mientras que por lo que hace a la versión de la Naturphilosophie que surge con Oken, Luis Montiel ha resaltado también la importancia de la idea de devenir, añadiendo que «Una Filosofía de la Naturaleza (la de Oken) entendida como «historia de la generación del mundo» (...) pone el acento en la concepción de dicha naturaleza como physis al modo presocrático, es decir, como generadora, y en consecuencia, es una physiolgía en el más amplio sentido del término» ${ }^{15}$, influencia de la filosofía presocrática que ha sido señalada igualmente para el conjunto de los naturphilosophen por Rafael Argullol ${ }^{16}$.

\section{Filosofía de la Naturaleza e Historia Natural en Augusto Gonzá- LEZ DE LINARES}

En la formulación de la Filosofía de la Naturaleza de la tradición krausista española tiene una importancia capital Augusto González de Linares (18451904). Linares, que era catedrático de Historia Natural en la Universidad de Santiago en 1875 cuando se promulga el decreto Orovio y junto con Laureano Calderón y Arana sería el primer profesor expulsado de la Universidad por la aplicación de este decreto es uno de los personajes de mayor relieve del grupo de naturalistas vinculados a la Institución Libre de Enseñanza y el que podemos considerar que sirve de enlace entre los miembros de la generación anterior, la de Giner, y la de los jóvenes que aprenden en la tradición krausista. Anfitrión de sus colegas de estas dos generaciones en su casa natal del Valle de Cabuérniga, tras la expulsión de unos y otros de sus puestos en la Universidad o en los Institutos, atrae con su fuerte personalidad a los estudiantes en las tertulias y debates del Ateneo de Madrid y en las que tenían lugar en la casa que Antonio Machado y Álvarez y Manuel Poley tenían en la calle del Olivo de la capital. Salvador Calderón reflejaría esa influencia al indicar que «fue siempre Linares para mí, hermano, maestro y modelo digno de imitación» ${ }^{17}$.

14 Duque, F. (1998), pág. 270.

15 Montiel. L. (1999), «Una Summa de la Filosofía de la Naturaleza del romanticismo alemán: El Lehrbuch der Naturphilosophie de Lorenz Oken (II), Asclepio, vol. LI-2, pág. 217.

16 Argullol, R. (1995), Naturaleza: La conquista de la soledad. Fundación César Manrique, Lanzarote, pág. 16

17 Calderón, S. (1904), «Augusto González de Linares», Memorias de la Sociedad Española de Historia Natural, nota leída en la sesión del 1 de junio de 1904 y reproducida en BILE, año 28, $n^{\circ}$ 534, 30 de septiembre de 1904. 
Director de la Estación de Biología Marítima de Santander desde su creación en 1887 hasta la muerte del naturalista en 1904, Linares escribió entre 1874 y 1879 algunos trabajos que le convierten en el principal sistematizador, junto con Alfredo Calderón y Arana, de la Filosofía de la Naturaleza del krausismo español ${ }^{18}$.

En 1879, Augusto González de Linares publica una serie de artículos en la Revista de España bajo el título común de «La geometría y la morfología de la Naturaleza» ${ }^{19}$. En ellos, el naturalista de la Institución Libre de Enseñanza se propone denunciar el «perversor influjo del sentido atomista» que estaba contenido tanto en la moderna Geometría, como en la teoría darwiniana de la pangénesis.

Recordemos que esta teoría surge en el contexto de las investigaciones que realiza Darwin en la década de 1860 sobre la herencia, como elemento indispensable para la explicación y el desarrollo de la teoría evolucionista. Darwin presentó esta teoría como una «hipótesis provisional» y a través de ella señalaba cómo cada parte del cuerpo procedía de partículas que denominó «gémulas», que circulaban por el cuerpo reuniéndose en los órganos sexuales. La reproducción tendría lugar cuando las gémulas de ambos padres se mezclaban en el óvulo fecundado y el embrión se desarrollaba mediante la fuerza de crecimiento propia de estas gémulas.

Se ha señalado ${ }^{20}$ que la pangénesis debe mucho a una teoría similar propuesta por Herbert Spencer a partir de las ideas de Richard Owen sobre la «partenogénesis» y que con esta teoría Darwin pretendía explicar muchos de los fenómenos de la herencia. Primero, que las diferencias individuales normales son aleatorias. Segundo, sugiere la herencia de los caracteres adquiridos. Tercero, los caracteres que se mezclan dependen de la dotación de gémulas procedente de cada progenitor. Cuarto, y a esto se refiere González de Linares como origen de los estudios que dieron lugar a la teoría de la pangénesis, permite explicar los rasgos atávicos que aparecen cuando un carácter presente en una generación, y luego oculto en las generaciones sucesivas, reaparece de nuevo en una generación posterior.

18 Acerca de Augusto González de Linares cfr. Madariaga de la Campa, B. (1984), Augusto González de Linares. Santander.

19 Estos artículos empiezan a aparecer en el no 222 de la Revista de España. Los dos a que nos vamos a referir aquí aparecen en el $t .66, \mathrm{n}^{\circ} 264,1879$, págs. $479-487 \mathrm{y}$ en el $t .69, \mathrm{n}^{\circ}$ 274, 1879, págs. 185-196.

20 Ruse, M. (1983), La revolución darwinista, Alianza, Madrid, págs. 267-268. 
González de Linares señala que la teoría de Darwin contiene un error que la penetra y vicia en absoluto y que ese error, oculto en El origen de las especies, por lo que había podido pasar desapercibido, queda explícito en las teorías sobre la herencia y en la formulación de la hipótesis de la pangénesis. Para Linares, la contradicción inherente a la teoría de Darwin está en que el científico británico no ha advertido que toda ella está encaminada a «explicar merced a una lentísima cooperación de dos factores, la adaptación y la herencia, aquello mismo que se muestra ya realizado sin el concurso de tales circunstancias en la última de estas funciones», en no reparar que «en el fenómeno de la reproducción de los organismos superiores, la del hombre, por ejemplo, una célula, la forma orgánica más sencilla, se convierte en un cuerpo humano adulto, la forma de organización más complicada, sin que medien para este cambio supremo ni la muchedumbre de siglos, ni la serie de influjos climáticos diversos, ni la cadena dilatada de generaciones en que hubieran debido irse acumulando estos por ley de fijación hereditaria» ${ }^{21}$.

La crítica de González de Linares a la teoría de Darwin no tiene, en nuestra opinión, nada que ver con la teoría de la recapitulación, con la llamada ley de Meckel-Serres, convertida luego, en la versión que le dio Haeckel, en la «ley biogenética fundamental», en el sentido de la relación existente entre ontogenia y filogenia y cómo el desarrollo del embrión contenía los sucesivos momentos de la evolución. Cuando el profesor de la Institución Libre de Enseñanza habla de que el desarrollo de la célula a través de la fecundación del óvulo da lugar, mediante un proceso evolutivo, a la formación de una forma superior, se está refiriendo a otra cosa. La célula contiene una energía interna que se despliega «al amparo de las sustancias y fuerzas que le ofrece el organismo progenitor, que es ahora su verdadero clima inmediato, el medio ambiente de su vida». No puede aceptar Linares que la íntima unidad de la naturaleza, que tanto había valorado como principal virtud de la teoría evolucionista, acabara siendo pervertida por un mecanismo evolutivo que actuaba a través de pequeñas variaciones producidas al azar que otorgaban alguna ventaja a sus poseedores y eran transmitidas a la descendencia en virtud de un procedimiento de exasperante lentitud en el que se acababa difuminando la unidad esencial de la naturaleza. La evolución es así, según la versión del científico krausista, un elemento contenido en la naturaleza, una fuerza vital, que estaría más en relación con la idea de Bergson del impulso vital $^{22}$ y la posterior teoría de la ortogénesis que con el darwinismo. Es, en defini-

21 GonZÁlez de LiNARES, A. (1879), pág. 485.

22 Algunos autores han resaltado la influencia de Schelling sobre Bergson. Así, Xavier Tilliette señala cómo en Francia «Charles Secrétan y sobre todo Ravaisson prolongan algunas 
tiva, una forma de entender la evolución en la naturaleza muy cercana a la idea schellingiana de impulso configurador (Bildungstrieb) ${ }^{23}$.

De esta forma, la pangénesis vino a completar la teoría darwinista al mecanizar y someter de lleno al proceso atomista la reproducción, despojándola del carácter orgánico, evolutivo, que ofrecía y que había pasado desapercibido al propio Darwin.

Linares rechaza además la pangénesis porque ve en ella la revitalización del dogma de la Creación al suponer la presencia de formas preexistentes en las gémulas de Darwin, supuesta preformación, dice, «contradicha por la experiencia y opuesta a la idea, la cual repugna concebir el mundo como grandioso mecanismo fabricado todo él de una vez por las manos del Supremo Hacedor» ${ }^{24}$.

A pesar de las críticas que la hipótesis de la pangénesis había recibido, Linares le augura un próspero futuro debido a la coherencia que proporciona al evolucionismo darwinista. Sin embargo, el predominio del atomismo acabará provocando una crisis en la biología que permitirá una vuelta hacia una concepción verdaderamente orgánica y unitaria del mundo natural, concepción que había iniciado la Naturphilosophie y que se había visto alterada por el predominio del atomismo del que la teoría darwinista era una representación. No obstante, no parece que la predicción de González de Linares en cuanto al éxito de la pangénesis se cumpliera. La teoría obtuvo pocos adeptos y pronto sería descartada por los desarrollos de la teoría celular ${ }^{25}$. El propio Darwin nunca la incluyó en las sucesivas ediciones de El origen de las especies, mientras que sus seguidores quedaron un tanto decepcionados con la formulación de esta «hipótesis provisional» ${ }^{26}$.

En la crítica de González de Linares a Darwin vuelven a presentarse los elementos que habían quedado antes de manifiesto en su crítica a Haeckel, expuesta en un curso sobre la Morfología de Haeckel impartido en la Institución Libre de Enseñanza entre marzo y junio de $1877^{27}$. De nuevo, González

\footnotetext{
intuiciones vivaces de Schelling y, a través de Ravaisson, Bergson pudo descubrir por instinto el devenir y el sentido schellingiano de la duración». TILLIETTE, X. (1977), «Schelling», en Belaval, Y. (dir.), Historia de la Filosofía Siglo XXI. Vol 7. La filosofía alemana, de Leibniz a Hegel. Siglo XXI, Madrid, pág. 410.

23 Cfr. DuQue, F. (1998), pág. 270.

24 GonZÁleZ DE LiNARES, A, (1879), pág. 193.

25 Bowler, P.J. (1995), Charles Darwin. El hombre y su influencia. Alianza, Madrid, pág. 155.

26 RUSE, M. (1985), pág. 268.

27 GonZÁlez de LinARES, A. (1877), «La Morfología de Haeckel: antecedentes y crítica», BILE, 1877, págs. 18-82.
} 
de Linares valora la aportación al estudio de la naturaleza que había hecho la Filosofía de la Naturaleza alemana y contrasta esta aportación, en la que queda resaltada la unidad orgánica del mundo físico, con la de Lamarck y Darwin, donde esta unidad tiene un carácter mecánico y el desarrollo de las formas naturales a partir de su unidad de origen viene determinada, no por una necesidad interna, sino por meros accidentes exteriores.

En la crítica que hace González de Linares a Haeckel la acusación principal que se lanza contra el profesor de Jena es la de materialismo. El error de Haeckel, dice Linares, «procede de concebir abstractamente la Materia como fondo general donde se informan los cuerpos, en vez de reportarla inherente al ser, al organismo de la Naturaleza, que la engendra de sí propio al determinarse mediante su actividad, desplegada luego en fuerzas y procesos, no de la Materia, sino de la Naturaleza misma» ${ }^{28}$.

De este error principal surgen otros en la construcción enciclopédica de Haeckel. «Los principales, sigue Linares, son los siguientes: 1) Confunde en círculo vicioso la Fuerza con el movimiento, pues estima aquélla resultado de éste, y a éste engendrado por aquélla; 2) Limita la Morfología de la Naturaleza a la de la Materia, esto es a la ciencia del espacio material olvidando que el tiempo y el movimiento son, como el espacio, formas naturales y sus ciencias respectivas entran en la Morfología natural; 3) Entiende la Química unas veces como la ciencia natural en su total integridad, y la reputa otras término mediador entre la Morfología y la Feronomía (la Física); 4) Hace de la vida un atributo peculiar de una esfera de la Naturaleza, afirmando una supuesta «Abiología» contradicha por las ideas y los hechos; 5) Divide también la ciencia natural en dos partes, telúrica y uránica, como Humboldt, desconociendo la subordinación de la Tierra al reino sidéreo; 6) Desconoce la identidad de la Geometría y la Morfología natural, pues no hay espacio vacío abstracto, sino lleno siempre de materia, y por lo tanto, sólo una ciencia debe tratarlo; 7) Niega a la Morfología descriptiva carácter de ciencia siguiendo la opinión de todo el idealismo respecto de la Historia, sin atender a que la ciencia exige sólo enlace sistemático orgánico, sea de ideas, sea de hechos» ${ }^{29}$.

Hemos considerado importante reproducir la lista completa de los «errores» de Haeckel porque de esta crítica va a surgir una especie de programa científico para los naturalistas surgidos en las filas del krausismo. La crítica de Haeckel formulada por González de Linares ejerce una poderosa influen-

28 GonZÁLEZ DE LinARES, A. (1877), «La Morfología de Haeckel: antecedentes y crítica». Conferencia del 4 de mayo de 1877, BILE, 1877, pág. 39.

29 GonZÁlEZ DE LinARES, A. (1877), BILE, 1977, pág. 39. 
cia en científicos como Salvador Calderón o Francisco Quiroga. Pero también hay que señalar que el sistema conceptual que se elabora de esta forma resulta claramente insuficiente para el desarrollo de la investigación científica y tanto Salvador Calderón como incluso el propio Linares serían conscientes de ello. Por eso, el sistema así constituido se convierte en una especie de superestructura ideológica, apriorística, pero situada prácticamente al margen del desarrollo concreto de la investigación, en la que científicos como Salvador Calderón se valen de un instrumental teórico más cercano al positivismo.

El estudio de González de Linares que más influencia va a ejercer, con todo, sobre los científicos de su entorno es su Ensayo de una introducción al estudio de la Historia Natural, publicado en 1874. Resulta significativo que tras la muerte de Augusto González de Linares, el Boletín de la Institución Libre de Enseñanza reprodujera este trabajo elaborado treinta años antes y que podemos considerar como verdadero documento fundacional de la Filosofía de la Naturaleza del krausismo español ${ }^{30}$ y ello por varios motivos. Primero, porque por su fecha precede a los demás escritos sobre filosofía natural que surgen en el entorno de los integrantes de la tradición krausista. Segundo, debido al sentido que González de Linares da al término Introducción, como veremos más adelante. En tercer lugar, por el carácter sistemático que tiene este escrito de Linares. En cuarto lugar, por la influencia que este texto ejerce sobre algunos naturalistas del entorno krausista e incluso sobre otros no tan directamente relacionados con ese entorno. Tal vez, también, el propio título nos deje un cierto recuerdo a la Introducción al Proyecto de un sistema de filosofia de la naturaleza (Ersten Entwurf eines System der Naturphilosophie) de 1799 en el que Schelling utiliza por primera vez el término Naturphilosophie y no el de Philosophie der Natur como había hecho en sus escritos anteriores.

González de Linares protesta aquí, en nombre de la unidad de la ciencia y la de la naturaleza, del carácter descriptivo y la «idolátrica adoración del pormenor atomístico» ${ }^{31}$ a que quedaban reducidas, en la mayoría de los casos, las ciencias. Este estado de cosas suponía además una incapacidad para proporcionar una visión adecuada de una realidad marcadamente unitaria y en la que el interés exclusivo por el detalle era muestra de la impotencia para desentrañar los elementos comunes y la unidad de origen de la naturaleza.

Si este error es común a diversas ciencias, más proclive es a él la Historia Natural, ya que, por su carácter descriptivo, tiende a olvidar la unidad, el sis-

30 GonZÁlez de LiNARES, A. (1905), BILE, págs. 247 y ss.

31 GONZÁlEZ DE LiNARES, A. (1905), BILE, pág. 247. 
tema, cuyos progresos en el estudio del detalle han sido tales que es difícil abarcar todos sus especiales asuntos a la vez, perdiéndose de vista también la unidad del conocimiento científico. Para acabar con esta situación es preciso una propedéutica, una Introducción, y este es el sentido del título del trabajo de González de Linares, que sea capaz de responder a dos preguntas. ¿Qué asunto tiene la Historia Natural? es la primera. ¿Cómo ha llegado a tener noticia de este objeto el indagador y cómo puede llegar a aplicarla en lo sucesivo?, la segunda ${ }^{32}$

De cada uno de estos asuntos se desprenden otras cuestiones subordinadas que constituyen el plan de trabajo de González de Linares. Con respecto al objeto de la Historia Natural, el profesor de la Universidad de Santiago aprecia tres aspectos: la formación del concepto de esta ciencia, las relaciones que unen a la Historia Natural con otras ciencias y la exposición del plan del contenido de la Historia Natural. Por lo que hace a la forma en que el investigador llega a tener conocimiento de este objeto distingue a su vez dos asuntos: los medios que permiten el acceso del objeto a la conciencia reflexiva del indagador, y el método que debe utilizar en el uso y dirección de estos medios para llegar a conocer en realidad y verdad el objeto.

En el estudio de la ciencia de la naturaleza, González de Linares establece dos niveles de conocimiento que es necesario no confundir, aunque sean complementarios y avancen a través de influencias recíprocas. Por un lado, la Historia de la Naturaleza, a la que incumbe tanto «trazar el cuadro que en la actualidad ofrecen a nuestra observación los diversos seres naturales como estudiar las transformaciones que hayan podido experimentar, v. gr., la Fauna o la Flora terrestre, desde su primera aparición hasta nuestros días». De este segundo punto de vista, al que llama genético, valora Linares el que «comienza hoy a alcanzar merecida estima, ya respecto de la Tierra, ya respecto de los seres que alternativamente la han poblado»».

Por otro lado, los conocimientos que se ocupan de lo que son los seres naturales en sí mismos, sin relación alguna al tiempo. A este género de conocimientos llama filosóficos y Filosofía a la ciencia donde se enlazan de un mo-

32 No podemos evitar encontrar cierta semejanza en esta pregunta que se hace González de Linares y en cómo la resuelve con la que se formula en un artículo anónimo titulado Über die Medizin. Arkesilas an Ekdemos, aparecido en 1795 en el periódico alemán Der Teutsche Merkur y que fue atribuido al médico J. B. Erhard, corresponsal de Kant y colaborador de Röschlaub, como señalan Elvira Arquiola y Luis Montiel y en la que se dice «¿Puede prometer gran certidumbre una ciencia que nunca ha ofrecido un concepto de su objeto». Cfr. Arquiola, E. y Montiel, L. (1993), págs. 77-78. 
do sistemático. De esta forma las preguntas ¿qué es un animal, qué es una planta? Tienen este carácter y sólo pueden ser contestadas en la Filosofía de la Naturaleza, y sigue diciendo que «la unidad de las fuerzas, en la Física; las cuestiones sobre el origen y evolución de los organismos terrestres, en la Historia Natural, pueden reputarse como las dos señales culminantes de una tendencia marcadamente filosófica en las Ciencias de la Naturaleza, aunque, por desgracia todavía harto vaga e incompleta, y desatendida por los más».

Ese doble nivel cognoscitivo necesario para la cabal comprensión de la naturaleza tiene una base concreta en la realidad compleja de los seres naturales. En este punto, la necesidad de compatibilizar una explicación puramente naturalista de la existencia y las relaciones entre los seres con la creencia en un plan providencial de la naturaleza, hace tambalearse la versión unitaria y monista que de la Historia Natural tenía González de Linares, llevándole hacia una contradicción que ejercerá su influjo sobre todo el naturalismo de la tradición krausista y que está en el origen también de esa ambigüedad metodológica que hemos apuntado antes. Así, el naturalista que poco después iba a ser expulsado de su cátedra por defender la libertad de la Ciencia frente a las exigencias del decreto y circular de Orovio, afirma que es necesario establecer, dentro de la inmensa variedad de seres que ofrece la naturaleza, cuál es la primera y más radical distinción que entre esos seres se observa y, empezando por atender a la propia naturaleza humana, encuadra que ésta «no es simple, sino compleja: que está formada por la composición de dos elementos, cuya oposición, armoniosamente unida en el que lleva por excelencia el nombre de ser racional, se despliega luego en el Universo, constituyendo los dos polos fundamentales de la Creación». Uno de esos elementos, el Espíritu, nos es inmediatamente presente y conocido en su esencia y vive «en sí y por sí, en medio de las influencias de todas clases que le rodean, a las cuales puede y debe sobreponerse, si son contrarias al cumplimiento de su destino», y el otro, el Cuerpo, sólo nos es conocido después de una larga y laboriosa experiencia y tiene fuerza de sí y en los otros seres su centro vital, de donde recibe los impulsos fundamentales a que obedece, en un red de influencias recíprocas que tiene por fundamento y principio inmediato a la Naturaleza que «con infinita virtud engendra y produce todas las criaturas, desde el cuerpo celeste al infusorio, según el plan providencial que cumple también ella en el Universo bajo el gobierno de Dios» ${ }^{33}$.

No obstante, la íntima interacción existente en todos los procesos naturales contribuye a restaurar en parte, a través de una última síntesis, la unidad perdida en virtud de esa dualidad entre la experiencia y la idea, convertida en

33 GonZÁlez de LinARES, A. (1905), BILE, pág. 280. 
relación dialéctica entre lo esencial y lo mudable. Fruto de esa síntesis, que supera la división del estudio de la naturaleza entre la Filosofía y la Historia, nace la Filosofia de la Historia de la Naturaleza.

El Ensayo de Linares acaba con el diseño del plan a que debe ajustarse el estudio de la Historia Natural, que abarca a todos los seres, tanto sidéreos como epitelúricos. Este plan será la base a la que se ajustarán más tarde los manuales que salgan de la pluma de los científicos del entorno de la Institución Libre de Enseñanza. En ellos se establece una sucesión entre el estudio de la Uranología, la Geología, la Fitología o Botánica, la Zoología y, reconociendo la existencia del reino hominal de que hablaba Quatrefages, la Antropología. A todo ello deben preceder algunas consideraciones generales destinadas a poner en claro la idea que se tiene de la Historia Natural, si bien estas cuestiones preliminares afectan más bien a la Filosofía de la Naturaleza.

\section{LA «NOVÍSIMA» FILOSOFÍA NATURAL ESPAÑOLA}

Junto a Augusto González de Linares, Alfredo Calderón y Arana (18501907) puede ser considerado el principal sistematizador de la Filosofía de la Naturaleza de tradición krausista en la España de los años setenta del siglo XIX. Al contrario que sus hermanos Laureano y Salvador (químico y cristalógrafo el uno, mineralogista y geólogo el otro), Alfredo Calderón no orientó sus estudios hacia las ciencias físico-naturales y permaneció alejado de la enseñanza oficial pese a haber aspirado en varias ocasiones a una cátedra de Derecho Natural en distintas Universidades españolas. Todo ello no fue obstáculo para que ejerciera una importante influencia pedagógica a través de su participación en la Institución Libre de Enseñanza y de sus artículos periodísticos sobre asuntos relacionados con la enseñanza y que estuviera especialmente atento al movimiento científico, fruto de lo cual es su obra Movimiento novísimo de la filosofía natural en España (1879) en la que da cuenta de la existencia de una nueva dirección de los estudios sobre la naturaleza en España y de la tarea de sus principales representantes, al tiempo que contribuye a fijar las bases teóricas de la Filosofía de la Naturaleza de tradición krausista ${ }^{34}$.

El trabajo de Alfredo Calderón se inicia con una exposición de los principios a que se debe ajustar la filosofía natural y los elementos que han rodeado

34 CAlderón y Arana, A. (1879), Movimiento novísimo de la filosofía natural en España. Este trabajo apareció en la Revista Europea, $t$. 13, primer semestre de 1879, números, 268, 269, 271, 272, 275, 276, 277, 278 y 279, y como publicación independiente en Madrid ese mismo año. Aquí vamos a utilizar la edición de la Revista Europea. 
la aparición de ese nuevo movimiento de la filosofía natural en España a que se refiere el título y sigue luego con el análisis crítico de los trabajos llevados a cabo por Augusto González de Linares en el campo de la Biología y en la exposición doctrinal de la nueva filosofía natural, por Enrique Serrano y Fatigati en el de la Física, por José Macpherson, Francisco Quiroga y Salvador Calderón en el de la Uranología y por el último de los ahora citados en cuanto a la Botánica y a las afinidades entre la vida animal y la vegetal, a través de sus estudios sobre nutrición vegetal.

En el planteamiento que hace Alfredo Calderón acerca de los principios que deben inspirar a esa nueva filosofía natural, vemos repetidos algunos elementos que ya hemos señalado a propósito de los trabajos de Augusto González de Linares, por lo que nos limitamos aquí a hacer un breve catálogo de ellos, sin volver sobre los argumentos ofrecidos.

Se trata de la idea de la unidad existente en la naturaleza, completada con la que debe regir en la ciencia, en la medida en que ésta aspira a acercarse a la realidad, la crítica de la aspiración universalista que caracterizaba al naturalismo contemporáneo y su intromisión en esferas del conocimiento que le eran ajenas, la recusación del atomismo, el empirismo, el mecanicismo y el materialismo, que habían viciado la investigación científica promoviendo, bien una dispersión de los estudios científicos y una diversificación de la naturaleza incompatible con esa idea de unidad a que nos referíamos, bien un dualismo que presenta falsas oposiciones en la naturaleza, niega la autenticidad de ésta y lleva, en último término, a la necesidad de recurrir a fuerzas misteriosas y desconocidas, cuando no sobrenaturales, para explicar la actividad de una naturaleza sometida a la imagen del caos, o, en fin, la defensa de la unidad de todos los seres naturales, negando con ello la división artificial y común que se establece entre los inorgánicos y los orgánicos.

En esta campaña que inicia Alfredo Calderón, se sitúan decididamente en el otro lado los representantes, tanto de los prejuicios de la tradición como de las tendencias científicas modernas que pervertían esa profunda unidad de la naturaleza, y entre ellos también los evolucionistas, y señaladamente Haeckel, de los que, al igual que hacía González de Linares, valora su concepción unitaria de los procesos naturales, pero rechaza su materialismo, que falsea esa unidad.

Al mismo tiempo, reaparece en el ensayo de Alfredo Calderón la idea de los procesos naturales como despliegue de fuerzas internas contenidas en la naturaleza, a través de la expresión de una «vitalidad sin límites que se ostenta y desborda por todas partes $\rangle^{35}$.

35 CAlderón y AranA, A. (1879), Revista Europea, $n^{\circ}$ 269, pág. 483. 
La novísima filosofía natural española tendría sus precedentes en «la tradición científica de una escuela representada por tan ilustres pensadores como Schelling, Oken y Carus, y que ha encarnado la más alta expresión del sentido orgánico en la Naturaleza», pero al mismo tiempo ofrece un carácter verdaderamente original y nacional, que conjuga tradición y progreso, al tiempo que ofrece una metodología en la que se armonizan la especulación y la experiencia. Así, si González de Linares representa una tendencia en la que, partiendo del puro racional concepto de la naturaleza, llega a determinar con toda precisión la doctrina verdaderamente orgánica, otros como Serrano y Fatigati forman parte de una corriente que, desde la observación experimental se eleva, a través de «tenaces y reiterados esfuerzos» a la concepción de más alta unidad, llegando al fin al mismo resultado.

Esta nueva dirección idealista de la ciencia natural se debe también «al general movimiento de los estudios filosóficos, recientemente iniciado en nuestra patria», y entre los hombres que han contribuido a ese despertar de los estudios filosóficos y científicos, cita Alfredo Calderón como especialmente relevante al «eminente ex-profesor de la Universidad de Madrid D. Francisco Giner de los Ríos», al que "son deudoras de algunas de sus más preciadas conquistas muchas ramas de la ciencia patria, y al cual, en lecciones dadas en cursos privados, y valiéndose del método socrático de la enseñanza íntima (...), ha iniciado el movimiento que nos proponemos exponer, arrojando en espíritus jóvenes y entusiastas la semilla profunda que ha producido después como fruto las nuevas concepciones de los naturalistas $»^{36}$.

Como final de la parte filosófica o doctrinal de su trabajo, Alfredo Calderón expone el objetivo de ésta que es «Exponer meramente las principales conclusiones que este sentido novísimo ha formulado, intentando mostrar toda su trascendencia en el estado actual del desarrollo de las ciencias de la Naturaleza». En cuanto a los motivos que le han llevado a emprender esta tarea, el profesor de la Institución Libre de Enseñanza apunta al «estado de relativa incultura y de desnivel intelectual en que nos hallamos todavía con respecto de las naciones más adelantadas (que hacía preciso) dar a conocer a propios y a extraños los generosos esfuerzos, muchas veces coronados por el éxito feliz, con que algunas personalidades intentan, no ya sólo elevar el nivel de la cultura nacional, sino servir a los intereses generales de la ciencia, conquistándonos de esta suerte un lugar distinguido en el movimiento general del pensamiento contemporáneo» ${ }^{37}$.

36 CAlderón y Arana, A. (1879), Revista Europea, $n^{\circ} 269$, pág. 486.
37 CALderón y Arana, A. (1879), Revista Europea, $n^{\circ}$ 269, pág. 486 
Se ocupa a continuación Alfredo Calderón de la nueva dirección de los trabajos en el campo de la Biología natural que responde a esta tendencia. Recogiendo la crítica antes mencionada a la aspiración universalista del naturalismo y volviendo sobre un asunto que antes hemos visto en González de Linares, Alfredo Calderón afirma que la Biología natural no es toda la Biología, ya que hay una vida fuera de la naturaleza, y añade que «no basta para conocer las leyes que rigen la vida espiritual, el mero estudio y aplicación como desde fuera, de las reconocidas con más o menos detenimiento en la de los seres naturales; aplicación que constituye actualmente una especie de neoescolasticismo o neo-dogmatismo naturalista, de que importa hacer cuanto antes pronta y debida justicia». Reconociendo la existencia de un dualismo entre Espíritu y Naturaleza, señala, sin embargo, que el que este dualismo no constituye «un verdadero antagonismo, ni una insoluble contradicción, es una verdad manifiesta: que las leyes que rigen uno y otro orden de seres son, no ya semejantes sino idénticas en el fondo, no es posible dudarlo; pero que la naturaleza propia de cada orden modifica profunda y radicalmente la manifestación en ellos de aquellas leyes comunes de la realidad, constituyendo una opuesta polarización, base de su íntima, indisoluble unión en la vida, es un principio no menos cierto, contra cuya evidencia se estrellarían eternamente todos los sofismas $\rangle^{38}$.

Para Alfredo Calderón, el objetivo principal de la Biología natural es establecer y desarrollar el concepto de vida y en este sentido la noción aportada por el novísimo naturalismo español viene determinada en la esfera natural por el carácter de encadenamiento, de enlace de todo con todo, en la que la unión en el ser mismo de los elementos de permanencia, sucesión y propia causalidad de sus estados son los caracteres necesarios y suficientes para que se pueda reconocer en él la vida.

Alfredo Calderón proporciona la versión más completa y acabada para la visión ortogenética del proceso evolutivo característica de la tradición krausista y que hemos visto formulada por Augusto González de Linares. El desenvolvimiento del ser «por propia e interna virtud» implica que este ser interno, potencial, virtual, dinámico, precede a su concreción exterior, positiva, material, sensible, de forma que el organismo material no es sino la manifestación determinada del organismo dinámico que «en relación con el medio le engendra, le desarrolla y le mata». Acercando el evolucionismo lamarckiano a su propia visión, Alfredo Calderón recoge el aforismo que se deriva de la teoría de Lamarck en cuanto a que «la función hace al órgano» para comple-

38 Calderón y Arana, A. (1879), Revista Europea, $n^{\circ}$ 271, pág. 546. 
tar su argumentación señalando que «no emana, por tanto, la vida del organismo, sino el organismo de la vida (...) es el ser mismo real, preexistente, esencial, el que de su propio fondo, si bien en necesaria relación y en cierto modo subordinación al medio (...) se encarna en ese medio natural, toma cuerpo y forma sensible en su seno, y en colaboración con él preside el desarrollo de ese organismo material y visible, imagen de su propio interno organismo dinámico, condición indispensable y adecuado teatro para la obligada relación entre aquellas dos vitalidades, - la del ser y la del medio natural en cuyo seno se desarrolla - puestas en necesario contacto y en perpetua y recíproca condicionalidad» ${ }^{39}$.

Como se desprende de lo anterior, el medio no constituye una realidad externa y ajena al ser, por lo que la perspectiva del proceso evolutivo como despliegue de las potencialidades contenidas en el ser no aparece perturbada por la necesidad de adaptación a un medio exterior, sino que, en palabras de Alfredo Calderón, «esto que abstractamente denominamos medio, no es en suma otra cosa que el ser natural mismo en cuyo interior y en cierta subordinación a las condiciones que impone su propia vitalidad, se desarrolla otro ser, que puede a su vez servir de medio para otro, constituyéndose de esta suerte los seres naturales en una serie infinita de posible subordinada mediatividad»».

Calderón destaca también la contribución realizada por González de Linares en su conferencia en la Institución Libre de Enseñanza sobre La vida de los astros a la idea de los individuos sidéreos como verdaderos seres naturales en los cuales la vida se manifiesta plenamente a través de su desenvolvimiento interior. De la afirmación de la vida como propiedad de los astros se derivan además consecuencias trascendentales, entre las que señala el plantear en otros términos el problema del origen de la vida, asunto que queda reducido al de la forma en que la vida se produce en seres individuales y concretos, dentro de otro ser concreto que se halla dotado de esa propiedad y deja de ser la cuestión a plantear la del origen de la vida para convertirse en la de la «aparición de la vida epitelúrica» ${ }^{40}$.

Tras hacer un recorrido por las contribuciones que han realizado a esa novísima filosofía natural española Enrique Serrano y Fatigati en el campo de la Física, José Macpherson, Francisco Quiroga y Salvador Calderón y Arana en el de la Geología, y este último en el de la Botánica, Alfredo Calderón se ocupa explícitamente de la repercusión del transformismo en España al hilo de su descripción de los nuevos estudios de Zoología, ciencia que lamenta no

39 CALderón y Arana, A. (1879), Revista Europea, $n^{\circ} 271$, pág. 548.
40 CALderón y Arana, A. (1879), Revista Europea, $n^{\circ} 272$, pág. 591. 
haya sido objeto de una atención semejante por parte de los naturalistas españoles. Esta carencia resulta tanto más notable cuanto que los estudios zoológicos estaban teniendo consecuencias trascendentales para la ciencia moderna $\mathrm{y}$, a propósito del transformismo, añade que «cualquiera que sea el juicio que semejante teoría deba merecernos no puede menos de aplaudirse la conducta leal de aquellos pocos naturalistas que se han declarado francamente sus partidarios arrostrando la enemiga, tan terrible aún entre nosotros, de los vulgares prejuicios».

En nota a pie de página, Alfredo Calderón señala entre los naturalistas que han defendido abiertamente la doctrina transformista a don Antonio Machado y Núñez y a don Rafael García Álvarez y las indicaciones más o menos explícitas contenidas en trabajos monográficos realizados por Eduardo Boscá y por Ignacio Bolívar y refiriéndose a las repercusiones que habían tenido las declaraciones realizadas por Machado y García Álvarez en ocasiones solemnes señala que «aquellas profesiones de fe científicas, apenas han servido entre nosotros de tema a ligeras y frívolas discusiones; más frecuentemente han sido origen de anatemas, tan ridículos como impíos, fulminados contra sus autores por una ciega, ignorante superstición» ${ }^{41}$.

Concluye su artículo Alfredo Calderón con una reflexión sobre la forma que había adoptado la polémica evolucionista en España, en la que señala la necesidad de formar un juicio serio y científico sobre el darwinismo que sirviera al menos para «remediar los males que acarrea el que semejantes cuestiones queden abandonadas al ligero y superficial examen del peor de los vulgos, de ese vulgo semiculto lleno juntamente de absurdas preocupaciones y de vana presunción, y cuya soberbia le incita a lanzar a cada paso excomuniones desautorizadas y huecas declaraciones contra doctrinas que radical y absolutamente desconoce, y esto no en conversaciones privadas ni en el seno de la intimidad, -única esfera en que son tolerables ciertas inepcias - sino en oraciones académicas, y a veces en discursos parlamentarios, que es verdadera afrenta hayan de ser conocidos y juzgados más allá de nuestras fronteras».

\section{El EVOLUCIONISMO ESPAÑOL EN UNA FASE MADURA DE SU DESARROLLO}

Hasta aquí hemos visto las formulaciones del pensamiento evolucionista de tradición krausista en sus orígenes, tal y como aparecía formulado en las versiones más autorizadas y ortodoxas de la escuela por parte de Augusto González de

41 Calderón y Arana, A. (1879), Revista Europea, $n^{\circ}$ 279, págs. 817-818. 
Linares y Alfredo Calderón y Arana. Dando un salto en el tiempo de más de veinte años, vamos a comentar hora la expresión del pensamiento evolucionista por parte de unos científicos que, recién comenzada su actividad en los años setenta del siglo XIX, se encontraban ya en plena madurez en el período del cambio de siglo. Se trata del manual redactado por Ignacio Bolívar y Salvador Calderón con el título de Nuevos elementos de Historia Natural ${ }^{42}$.

Antes de analizar la idea de evolución que aparece contenida en este trabajo, es conveniente precisar que a Ignacio Bolívar (1850-1944), aunque cercano siempre al entorno de los científicos de la Institución Libre de Enseñanza, no se le puede considerar como integrante de la misma escuela de pensamiento que el núcleo central de ella. Discípulo de Laureano Pérez Arcas, Bolívar se orientó sobre todo hacia los estudios de entomología y durante su época de estudiante realizó numerosas expediciones en compañía de otros jóvenes naturalistas como Salvador Calderón, de lo que resultaría una amistad entre ambos que no se interrumpiría a lo largo de sus vidas ${ }^{43}$. En 1871 participó en la fundación de la Sociedad Española de Historia Natural, que al celebrar en 1946 los setenta y cinco años de su existencia, convirtió este acontecimiento en un homenaje a Bolívar, muerto dos años antes en el exilio en México y silenciado por la cultura oficial en esos momentos. Ese mismo año de 1871 participa junto a Salvador Calderón, Eduardo Boscá, Francisco Quiroga y otros amigos en la creación del Ateneo Propagador de las Ciencias Naturales. Desde muy pronto, Bolívar muestra su proximidad al evolucionismo y ya en 1876, con motivo de su presentación a las oposiciones para la cátedra de Entomología de la Universidad Central, al referirse a la división hecha por $\mathrm{Cu}$ vier del reino animal en cuatro grupos (Vertebrados, Moluscos, Articulados y Zoófitos) que corresponderían a planes distintos de la Creación, indica que «La adopción de esta teoría nunca fue completa y en vida del mismo Cuvier, Lamarck y Geoffroy defendieron opuestas ideas (...) pretendiendo (...) que las especies no son fijas, ni los grupos tienen otro valor que el que le asigna el espíritu sistemático del hombre explicando la diversificación de los organismos por una modificación gradual e insensible de las especies, opinión que fue en parte la de algunos filósofos de la naturaleza y que en su esencia no se

42 Bolívar y Urrutia, I; CAlderón y Arana, S. (1900), Nuevos elementos de Historia Natural, Madrid. Este manual es una nueva edición del publicado diez años antes por los autores en colaboración con Francisco Quiroga, fallecido en 1894.

43 Acerca de Ignacio Bolívar, cfr. Alberto Gomis (pr.) (1988), Ignacio Bolívar y las ciencias naturales en España. Presentación y Apéndice de Alberto Gomis Blanco. CSIC, Madrid. Se trata de una edición facsímil de la realizada en 1921 con motivo de la jubilación de Bolivar. 
distingue realmente de la doctrina de Darwin si bien este último naturalista hace jugar en ella elementos como la selección natural y la lucha por la existencia que no se mencionan en los sistemas anteriores», añadiendo que la Ciencia no podía seguir aceptando el grupo de los articulados tal y como lo había presentado Cuvier ${ }^{44}$.

Por su parte, Salvador Calderón y Arana (1851-1911), aunque sí pertenecía a la tradición krausista, fue depurando considerablemente sus primitivas concepciones a medida que avanzaba su experiencia investigadora. Tercero de los hijos del matrimonio formado por el periodista Antonio María Calderón y María Ignacia Arana, Salvador Calderón se licenció en la Facultad de Ciencias de la Universidad de Madrid, sección de Naturales en 1872, obteniendo el grado de Doctor en la misma Facultad y sección ese mismo año ${ }^{45}$.El 24 de mayo de 1874 era nombrado por oposición catedrático de Historia Natural del Instituto de Las Palmas, puesto en el que se encontraba cuando el 26 de febrero de 1875 se publicó el decreto y circular de Orovio, ante el que protestaría, lo que llevaría a su suspensión de empleo y sueldo el 16 de junio de 1875, iniciándose así un período de alejamiento de la enseñanza oficial durante el que participaría en la fundación de la Institución Libre de Enseñanza y luego realizaría un periplo por varias capitales europeas y Nicaragua, donde participó en la fundación del Instituto de Occidente. Al regresar de Nicaragua en 1881, habiéndose producido el cambio de gobierno que permitió la reincorporación de los profesores expulsados por el decreto Orovio, Calderón fue nombrado catedrático de Historia Natural del Instituto de Segovia, logrando más tarde (1884) la cátedra de la misma materia en la Universidad de Sevilla, donde sustituyó a Antonio Machado y Núñez, hasta que en 1895 obtuvo la de Mineralogía y Botánica de la Universidad Central. Salvador Calderón es, sobre todo, mineralogista y geólogo, pero de su producción científica merecen destacarse también, en relación con el evolucionismo, sus estudios sobre nutrición vegetal a finales de la década de 1870, que son contemporáneos de los que sobre el mismo asunto realizaba Darwin como desarrollo de su teoría de la evolución ${ }^{46}$.

44 Expediente personal de Ignacio Bolívar y Urrutia. Archivo General de la Administración, Sección de Educación y Ciencia (AGA-EC), Legajo 196-27, Caja 15.399.

45 Sobre Salvador Calderón, cfr., Hernández Pacheco, E. (1911), «El profesor Salvador Calderón y Arana y su labor científica», BILE, págs. 353-365; Casado de Otaola, S. (2001), La escritura de la naturaleza. Antología de naturalistas españoles 1868-1936, Caja Madrid, Madrid; y Simó Ruescas, J. (1998), La institucionalización de la ciencia en España. Tesis Doctoral (inédita), Universidad Complutense, Madrid.

46 CALDERÓN Y ARANA, S. (1876), «Consideraciones sobre la alimentación de los vegetales en relación con los descubrimientos de las plantas carnívoras», Anales de la Sociedad 
Este breve esbozo biográfico sobre Ignacio Bolívar y Salvador Calderón nos puede servir para comprender más adecuadamente las semejanzas que puedan existir con los planteamientos de Augusto González de Linares y Alfredo Calderón y Arana analizados anteriormente y para que resulten menos extrañas las divergencias.

Bolívar y Calderón empiezan por definir la especie como el conjunto de «todos los individuos nacidos unos de otros por cualquiera de los medios reproductores, individuos que convienen entre sí en presentar los mismos caracteres» ${ }^{47}$. Advierten, no obstante, de la dificultad de fijar el concepto científico de la especie y consideran imprecisa e insuficiente la definición dada por Cuvier. Inmediatamente explican los imprecisos límites entre variedades y especies y los efectos de la selección natural a la hora de fijar las variedades y especies y los de la selección artificial en cuanto a las variedades, al tiempo que ilustran con algunos ejemplos la forma en que actúa la selección natural, deteniéndose, como un caso especial de adaptación, en la explicación del mimetismo cromático, del que Salvador Calderón se había ocupado en algunos estudios ${ }^{48}$. Aunque no se explica con precisión la forma en que actúa la selección natural, del tratamiento que se da a los ejemplos presentados y de lo que se dice más adelante se deduce la completa aceptación del proceso de selección natural de variaciones producidas al azar que se transmiten a la descendencia y se perpetúan en la medida en que proporcionan una ventaja. Los autores sí explican detenidamente el concepto de lucha por la existencia, señalando que «los individuos más débiles o menos fecundos en unos casos, o los que menos se adaptan al medio en otros, sucumben en esa lucha por la existencia entablada por los organismos unos con otros y todos con el medio en que viven ${ }^{49}$ y desvelan el origen malthusiano del mecanismo propuesto por Darwin al señalar que los organismos se esfuerzan por «multiplicar su especie engendrando un número de descendientes mucho mayor de los que llegarán a su completo desarrollo; pero a medida que esta fecundidad es mayor, crecen los riesgos de destrucción, sin lo cual sus individuos,

Española de Historia Natural, t. 5, Actas, págs. 98 y ss.; Calderón y Arana, S. (1879), «Respuesta a algunas objeciones a la teoría de la alimentación foliáceo-radical de los vegetales», Anales de la Sociedad Española de Historia Natural, t. 8, Actas, Págs. 76 y ss.

47 Bolívar y Urrutia, I; CALderón y Arana, S. (1900), Biología, pág. 43. Este manual está dividido en tres seciones: Geología, Biología (que incluye la Botánica) y Zoología, cada una de ellas con numeración de páginas independiente.

48 CALDERÓN Y ARANA, S. (1894), «Observaciones sobre el mimetismo cromático cambiante», Anales de la Sociedad Española de Historia Natural, t. 23, Actas, págs. 20-23

49 Bolívar y URRUTiA, I.; CALDERÓN y ARANA, S. (1900), Biología, págs. 45-46. 
multiplicándose en proporción geométrica, no hallarían comarca en el globo capaz de bastar a su alimentación»».

Con respecto a la herencia, estos Nuevos elementos de Historia Natural reflejan las incertidumbres en que se movía la teoría evolucionista con respecto a este asunto, que no se empezaría a resolver hasta que el desarrollo de la genética mendeliana permitiera una síntesis entre ésta y la teoría de la selección natural, base de la moderna teoría de la evolución, al menos desde un determinada perspectiva. Bolívar y Calderón admiten la herencia de los caracteres adquiridos y aclaran que para que estos se perpetúen es necesario «que sigan obrando sobre los descendientes las mismas causas que ocasionaron la desviación, por que en el caso contrario, aquel carácter, adquirido accidentalmente, volvería de nuevo a desaparecer por regresión al tipo primero».

Todo ello les lleva a defender una teoría de la evolución que entiende que «la variedad de formas vegetales y animales que hoy conocemos (...) son debidas a desviaciones y modificaciones de formas primitivas elementales que, evolucionando en el transcurso del tiempo y obedeciendo a las variadísimas condiciones a que pueden haberse hallado sometidas, siempre bajo el imperio de las leyes biológicas, hayan venido a producir el infinito número de formas vivas diversas que hoy conocemos, así como el de otras muchas que ni siquiera habrían dejado su huella en los estratos terrestres» ${ }^{50}$.

El carácter didáctico del manual les lleva a referirse a otras teorías propuestas para explicar la sucesión de las formas, la de las creaciones sucesivas y la de las emigraciones de las faunas, teorías que rechazan. La primera, por no estar de acuerdo con los hechos y por no tener en cuenta ni explicar «las profundas modificaciones que se realizan gradualmente ante nuestros ojos en los animales domésticos y en las plantas cultivadas y que gradualmente se producen en los seres en libertad», y la segunda, porque si las faunas y floras hubiesen emigrado, podría seguirse la pista de su recorrido y el parecido que muestra la fauna y flora de algunas regiones del planeta con las de anteriores períodos geológicos sería sólo por algunos rasgos generales de ellas y el predominio de ciertos grupos de animales y plantas, pero no por constar de las mismas especies. Estas afirmaciones suponen una cierta contradicción con la idea antes expuesta del origen común a partir de unas cuantas formas primordiales, contradicción derivada de las dificultades existentes a la hora de establecer los términos de la distribución geográfica de las especies que ya se habían dejado notar en la obra de Darwin.

50 Bolívar y Urrutia, I.; CAlderón y Arana, S. (1900), Biología, págs. 46-47. 
El paralelismo haeckeliano entre filogenia y ontogenia aparece también planteado en la obra de Calderón y Bolívar, paralelismo que llevaba en su desarrollo lógico a la formulación de la teoría de la recapitulación, que aparece expresada en estos términos: «se ha comprobado que entre la ontogenia y la filogenia, o sea, el desarrollo de las especies en el transcurso del tiempo, existe cierta relación constante y directa que pudiera expresarse diciendo que ambas son paralelas, siendo la ontogenia a modo de una reproducción o repetición abreviada de la filogenia, o en otros términos, que todo ser al desarrollarse sigue una marcha paralela a la que recorrió en el tiempo la rama genealógica a que pertenece, pero más reducida, esto es, sin presentar todas las fases correspondientes a aquella rama, que es lo que se trata de expresar con el calificativo de «abreviada»«.

La aceptación de este planteamiento tal y como había sido formulado por Haeckel no implicaba, sin embargo, aceptar al mismo tiempo el de la «escala del ser» en la forma en que había sido desarrollada por el profesor de Jena, como un elemento coherente con la lógica de la recapitulación. Por el contrario, los naturalistas españoles se muestran más de acuerdo con un modelo de divergencia que muestra una clara similitud con el célebre esquema presentado por Darwin en El origen de las especies en el que la evolución era concebida de una forma no lineal, sino con ramificaciones irregulares, lo que le servía para establecer su metáfora sobre «el árbol de la vida», o más bien «el coral de la vida». De acuerdo con esto, Bolívar y Calderón señalan que las formas vivientes son como «los extremos floridos de las infinitas ramas del árbol de la vida, del que muchas han muerto en épocas anteriores sin dejar sucesión, así es que la relación entre las especies vivas es como la existente entre las mismas provincias de una misma nación, no siendo, por tanto posible, colocarlas todas en una serie lineal (escala animal o vegetal) como se pretendía no hace muchos años ${ }^{51}$.

Como conclusión de la teoría de la evolución que habían expuesto en su obra, los dos naturalistas, que pretendían con ella dar una formación inicial, preparatoria, a los estudiantes de Ciencias de la Universidad española, indican que «cualquiera que sea el valor que se concede a la teoría de la descendencia, del transformismo o de la evolución, que con todos estos calificativos se conoce la teoría que tan a grandes rasgos hemos expuesto y de la que ha sido fundador el naturalista inglés Carlos Darwin, en su famosa obra sobre El origen de las especies, siquiera no le corresponde el mérito de la completa originalidad de ella, puesto que fue entrevista o presentida por otros naturalistas

51 Bolívar y Urrutia, I.; Calderón y Arana, S. (1900), Biología, págs. 48-50. 
anteriores a él, es innegable para dar un impulso grande a las ciencias biológicas, al que se debe el considerable desarrollo que hoy alcanzan ${ }^{52}$.

Todo ello muestra la forma en que era recibida la teoría de Darwin en España cuatro décadas después de la aparición de El origen de las especies y cerca de treinta años más tarde de que aparecieran las construcciones teóricas, procedentes del entorno krausista, de una Filosofía de la Naturaleza que recogía del darwinismo lo que tenía de concepción unitaria de la naturaleza, pero que rechazaba su materialismo. Al mismo tiempo, el manual de Ignacio Bolívar y Salvador Calderón nos permite observar cómo era expuesta la teoría de la evolución en una obra destinada a la formación inicial de jóvenes científicos, cuando además la explicación del darwinismo estaba lejos de ser aceptada por el bloque de poder dominante, como el conflicto suscitado a raíz de la inclusión en el Índice de los manuales de Odón de Buen se había encargado de demostrar poco antes ${ }^{53}$.

De este trabajo podemos destacar la desaparición de la idea de la evolución como desenvolvimiento del ser y de la apelación a un impulso interior de orden metafísico como causa de ese despliegue y, por el contrario, el sometimiento de todo el proceso a las leyes biológicas. Hay también, con todo, una influencia de la versión haeckeliana de la evolución, ya que había sido esa versión la más difundida en España por encima de la del propio Darwin. Pero al mismo tiempo, el planteamiento del autor de la Morfología de los organismos aparece despojado de su carácter finalista, mientras que hay, como ya se ha indicado, una interpretación mucho más ajustada del proceso de divergencia descrito por Darwin. En definitiva, los continuadores de la Filosofía de la Naturaleza de la tradición krausista a la altura de los años del cambio de siglo van despojándose, siquiera sea de manera limitada, de parte del equipaje metafísico con que esta escuela había incorporado el evolucionismo a su sistema filosófico durante la década de 1870 a partir de las contribuciones realizadas principalmente por Augusto González de Linares y Alfredo Calderón y Arana.

52 Bolívar y Urrutia, I.; Calderón y Arana, S. (1900), Biología, pág. 50.

53 Sobre el conflicto surgido a propósito de la prohibición de los manuales de Odón de Buen cfr. de BuEN, O. (2003), Mis memorias (Zuera, 1863-Toulouse, 1939), Institución Fernando el Católico, Zaragoza, págs. 62-65; ARQUÉS, J. (1984), «Els veritables fets sobre la suspensió del científic darwinista Odón de Buen de la seva cátedra de la Universitat de Barcelona el 1895», Actas II Congreso de la Sociedad Española de Historia de las Ciencias, vol. I, págs. 285-303, Zaragoza; y SIMÓ RUESCAS, J. (1999), «Ciencia, ideología y conflicto político. La polémica evolucionista en España a través del diario republicano La Justicia (1888-1897)», Cuadernos de Historia Contemporánea, número 21, págs. 213-225, Universidad Complutense de Madrid. 